\title{
Current status and perspective of CAR-T and CAR-NK cell therapy trials in Germany
}

\author{
Nawid Albinger $\mathbb{1}^{1,2} \cdot$ Jessica Hartmann $\mathbb{1}^{3} \cdot$ Evelyn Ullrich $\mathbb{1}^{1,2,4,5}$
}

Received: 21 September 2020 / Revised: 8 January 2021 / Accepted: 18 February 2021 / Published online: 22 March 2021

(c) The Author(s) 2021. This article is published with open access

\begin{abstract}
Chimeric antigen receptor (CAR)-T cell therapies are on the verge of becoming powerful immunotherapeutic tools for combating hematological diseases confronted with pressing medical needs. Lately, CAR-NK cell therapies have also come into focus as novel therapeutic options to address hurdles related to CAR-T cell therapies, such as therapy-induced side effects. Currently, more than 500 CAR-T and 17 CAR-NK cell trials are being conducted worldwide including the four CAR-T cell products Kymriah, Yescarta, Tecartus and Breyanzi, which are already available on the market. Most CAR-T cell-based gene therapy products that are under clinical evaluation consist of autologous enriched T cells, whereas CAR-NK cell-based approaches can be generated from allogeneic donors. Besides modification based on a second-generation CAR, more advanced CAR-immune cell therapeutics are being tested, which utilize precise insertion of genes to circumvent graftversus-host disease (GvHD) or employ a dual targeting approach and adapter CARs in order to avoid therapy resistance caused by antigen loss. In this review, we are going to take a closer look at the commercial CAR-T cell therapies, as well as on CAR-T and CAR-NK cell products, which are currently under evaluation in clinical trials, that are being conducted in Germany.
\end{abstract}

\section{Background on chimeric antigen receptor (CAR) therapy}

For decades the only available cancer treatments were surgical resection as well as chemotherapy and/or radiotherapy [1]. However in the last years, immunotherapies using immune-checkpoint inhibitors (ICI), as well as cellular therapies, have moved into the limelight as

Evelyn Ullrich

evelyn.ullrich@kgu.de

1 Children's Hospital, Division for Stem Cell Transplantation, Immunology and Intensive Care Medicine, Goethe-University Frankfurt, Frankfurt am Main, Germany

2 Experimental Immunology, Goethe University Frankfurt, Frankfurt am Main, Germany

3 Division of Medical Biotechnology, Paul-Ehrlich-Institut, Langen, Germany

4 Frankfurt Cancer Institute, Goethe University, Frankfurt am Main, Germany

5 German Cancer Consortium (DKTK), Partner Site Frankfurt/ Mainz, Frankfurt am Main, Germany promising alternative treatments. Normally, potentially malignant cells are continuously eliminated by the immune system, but cancer cells can accumulate certain mutations, which allow them to escape these mechanisms [2]. Cancer immunotherapies aim to support or boost the patient's immune system to enable the effective clearance of cancer cells.

One way to achieve this is to genetically modify immune cells, mainly $\mathrm{T}$ cells and recently also natural killer (NK) cells, to express chimeric antigen receptors (CARs). CAR-expression on T or NK cells allows them to specifically target cancer cells via recognition of tumor associated antigens. "Classical" CARs consist of an extracellular binding domain mostly derived from a monoclonal antibody fragment (single-chain variable fragment-scFv), which is linked to intracellular binding domains of the T-cell receptor complex. Binding of a tumor antigen via the $\mathrm{scFv}$ activates the $\mathrm{T}$ cell in a major histocompatibility-independent manner which leads to a cytotoxic response [3]. Novel CAR constructs are being continuously developed, which can possess altered intracellular co-stimulatory domains and/or targeting domains. Latter can consist of different molecules, such as nanobodies, designed ankyrin repeat proteins (DARPins), 


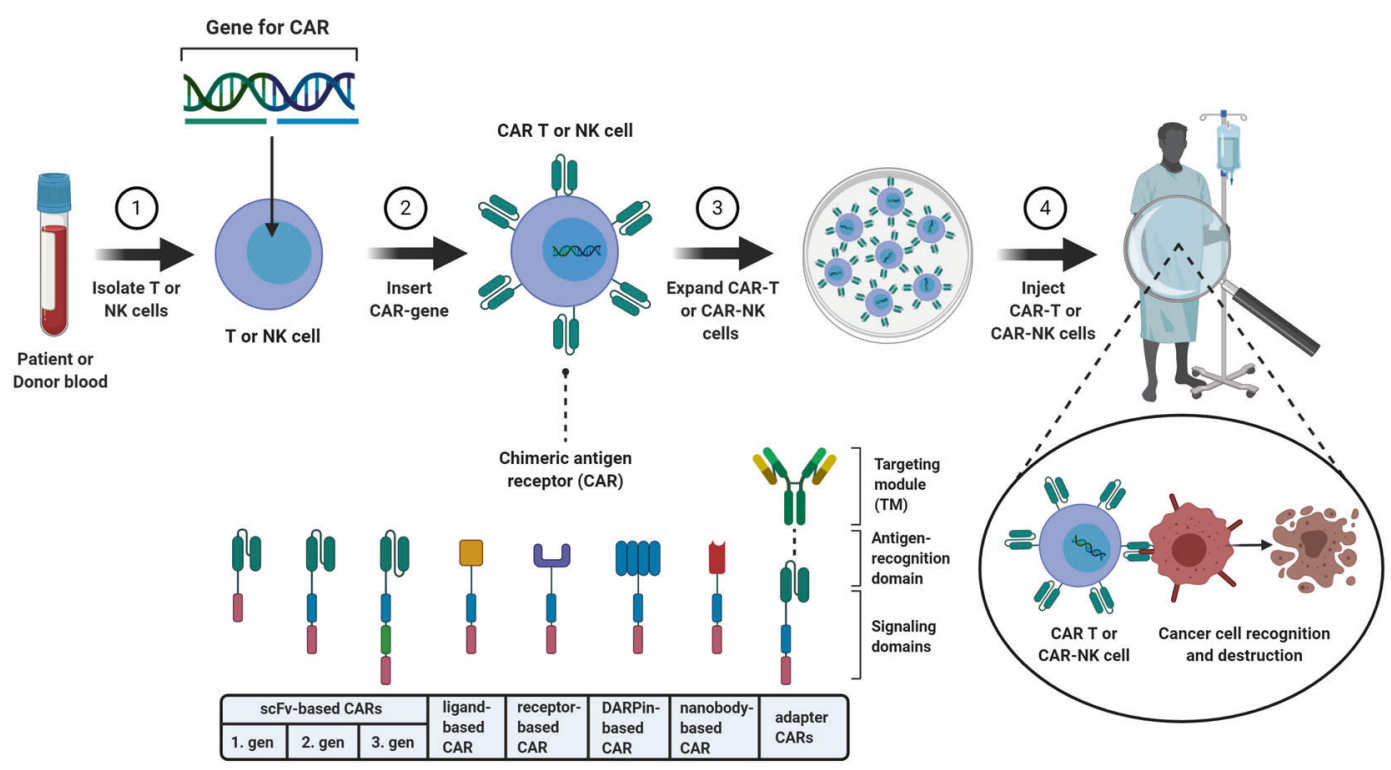

Fig. 1 Schematic illustration of a CAR-T or CAR-NK cell therapy, which uses primary immune cells. (1) T or NK cells are isolated from the patient's or donor's blood. (2) Subsequently, cells are genetically modified to express chimeric antigen receptors (CARs). (3) CAR-T or CAR-NK cells are expanded until sufficient cell numbers are attained and (4) (re-)injected into the patient's body, where they can fight cancer cells. CAR constructs possess a targeting module that recognizes tumor antigens and either a single intracellular signaling domain (1. gen) or, one (2. gen), or two (3. gen) additional co- stimulatory domains. In most CAR constructs the targeting module consist of a single-chain variable fragment $(\mathrm{scFv})$. Novel CAR constructs can also possess nanobodies, designed ankyrin repeat proteins (DARPins), ligands, or receptors instead of scFvs for target recognition. Adapter CARs consist of two components: a soluble antigen targeting module (TM) and a CAR which targets this TM. CAR chimeric antigen receptor, DARPins designed ankyrin repeat proteins, gen generation, $\mathrm{scFv}$ single-chain variable fragment, TM targeting module. This figure has been created using BioRender. ligands, or receptors instead of scFvs [4-7]. Furthermore, the so-called adapter CARs have been developed by splitting antigen recognition and CAR-immune cell activation. The addition of separate adapter molecules (AMs) specific for tumor antigens and CAR-immune cells targeting these AMs allows a more precise and temporally limited therapy. Thereby, several antigens can be targeted at once and the therapy can be adapted in case antigenloss tumor variants appear. Additionally, this approach opens the possibility to shut down the immune response if severe side effects emerge $[8,9]$.

An autologous CAR-T or NK cell therapy comprises several steps as shown in Fig. 1. First, T or NK cells are isolated from patient's or donor's blood. Subsequently, cells are transduced with CAR-encoding genes using (mostly) viral vectors. CAR-modified immune cells are expanded until sufficient cell numbers are attained and are adoptively transferred into the patient to fight malignant cells. Prior to infusion of the CAR-modified immune cells, lymphodepletion is performed in most therapeutic settings to allow efficient cell engraftment [10]. It is important to mention that, CAR-NK cells offer the potential to be an "off-the-shelf" product, but also allogeneic CAR-T cell therapies are currently under development [11-14].

\section{Overview of CAR-T and CAR-NK cell therapies worldwide}

CAR-T cells have shown astonishing results in the treatment of mostly relapsed or refractory $(\mathrm{r} / \mathrm{r})$ hematological malignancies, which have already resulted in the approval of three drugs by the U.S. Food and Drug Administration (FDA) and the European Commission (EC) between 2017 and beginning of 2021 [15-17]. Currently, a fourth CAR$\mathrm{T}$ cell product is under evaluation in Europe, which has been approved by the FDA lately [18]. Based on these crowning achievements, many CAR-T cell therapies are currently under evaluation worldwide. In total, over 500 clinical trials analyzing CAR-T cells for the treatment of cancer are currently being conducted around the world. Thereof, the majority are being performed in East Asia (269 trials), followed by the US (225 trials), and Europe with 62 ongoing studies (as registered at clinicaltrials.gov, Q3 2020).

Additionally, treatments with CAR-NK cells are becoming an alternative therapy option to CAR-T cells, as they possess certain advantages such as an intrinsic killing capacity of malignant cells and only few side effects post transplantation [19-22]. However, while a multitude of CAR-T cell therapies exist, still only relatively few CAR- 
NK cell trials are conducted worldwide. Currently, 19 trials investigating CAR-NK cells for the treatment of hematological malignancies as well as for the treatment of solid tumors are listed on clinicaltrials.gov. Most of the CAR-NK cell trials are conducted in China (15 trials), while three trials are ongoing in US, and only one trial is performed in Europe (Germany). In addition, a few trials are currently addressing CAR-NK/T cell products ( 2 trials in the US and 1 trial in China) as well as CAR-modified cytokine induced killer cells ( 1 trial in Italy).

\section{Current status of CAR-T and NK cell therapies in Germany}

In Germany, 29 clinical trials are currently being conducted which evaluate CAR-modified immune cells, including two long-term follow-up (LTFU) studies. Furthermore, five studies have been completed or terminated to date (Table 1). Most of the trials investigate CAR-T cell products for the treatment of B-cell malignancies. But also other indications such as melanoma, acute myeloid leukemia (AML), and multiple myeloma (MM) are being evaluated. In addition, one ongoing CAR-NK cell study addresses the impact of CAR-NK92 cells in glioblastoma patients. In the following sections, a short description of the CAR-T and -NK cell trials conducted in Germany is provided. If not otherwise specified, information is derived from the European Clinical Trials Register clinicaltrialsregister.eu or from the US based trial register clinicaltrials.gov.

\section{CAR-T cell therapies}

\section{CAR-T cells to target B-cell malignancies}

The human CD19 antigen is a $95 \mathrm{kd}$ transmembrane glycoprotein which belongs to the immunoglobulin superfamily without any known homology for other proteins [23]. CD19 positive cancers include diseases with highpriority medical needs such as r/r B-cell acute lymphoblastic leukemia (B-ALL), B-cell chronic lymphocytic leukemia (B-CLL), B-cell Non-Hodgkin lymphoma (B-NHL), and other B-cell malignancies. As CD19 is a Bcell-specific surface protein that is expressed throughout B-cell development, it is present on most B-cell malignancies and therefore a suitable target for CAR-T cell therapies [24]. Thus, in most clinical cell therapy trials for treatment of B-cell malignancies, CAR-T cells are used which are engineered to express CD19-specifc CARs. In addition to that, two studies are being conducted which deploy $\mathrm{T}$ cells expressing either CD20-CARs or CD19/ CD20-dual-CARs.

\section{Kymriah}

The approval of Tisagenlecleucel (market name Kymriah ${ }^{\oplus}$ lab code CTL019 or tisa-cel; producer: Novartis AG) in August 2017 by the FDA as first-in-class therapy set a milestone in cancer therapy [25]. Nearly 1 year later, in August 2018, Kymriah also received approval in Europe by the EC [26, 27].

Kymriah is generated from autologous CD4/CD8 T-cell enrichment of peripheral blood mononuclear cells (PBMCs) which are further transduced using a lentiviral vector. The vector encodes a second-generation CAR harboring the $\mathrm{scFv}$, derived from the CD19-specific monoclonal antibody FMC63 and the co-stimulatory domain from 4-1BB in conjunction with the signaling domain from CD3zeta $[23,26]$.

Kymriah is applied as therapy for patients up to 25 years with $\mathrm{r} / \mathrm{r}$ B-ALL and adult patients with $\mathrm{r} / \mathrm{r}$ large B-cell lymphomas after two or more lines of systemic therapies. Treatments with Kymriah have already achieved striking results with initial complete-response rates of more than $80 \%$ for the indication r/r B-ALL [28, 29]. Results for the treatment of diffuse large B-cell lymphoma (DLBCL) demonstrated a higher response durability compared to the historical control [26, 28]. At the moment, seven clinical trials along with one LTFU study of Kymriah are being conducted in Germany.

The approval of Kymriah is based on the phase II, single arm, multicenter study ELIANA (NCT02435849) for the indication B-ALL and on the phase II open-label, multicenter, single-arm study JULIET (NCT02445248) for the indication DLBCL [26], which were conducted in Germany as well. Clinical trial sites were located in Frankfurt and Cologne (ELIANA) and Würzburg (JULIET).

To further collect data on the efficacy of Kymriah in a BNHL setting, the post-authorization study BELINDA (NCT03570892), a phase 3, randomized, controlled trial of Kymriah versus standard-of-care chemotherapy is currently performed across the US, Australia, Germany, Japan, and Spain with a target enrollment of 318 patients. Seven different trial sites participate in Germany (e.g., Regensburg, Berlin, Hamburg) and intend to include 37 patients.

Another phase III multicenter study is currently ongoing in several different countries in Europe as well as in Canada and Japan treating children and young adults suffering from B-ALL (NCT03123939). In Germany, the trial is already completed. In total, five patients were intended to be treated at the clinical site in Frankfurt. Outcomes in this study remain mostly consistent with those in ELIANA [30].

At the moment, two further multinational, multicenter, phase II studies with Kymriah are ongoing in Germany investigating its use for adult patients suffering from $\mathrm{r} / \mathrm{r}$ follicular lymphoma (FL) and the feasibility to treat first-line 


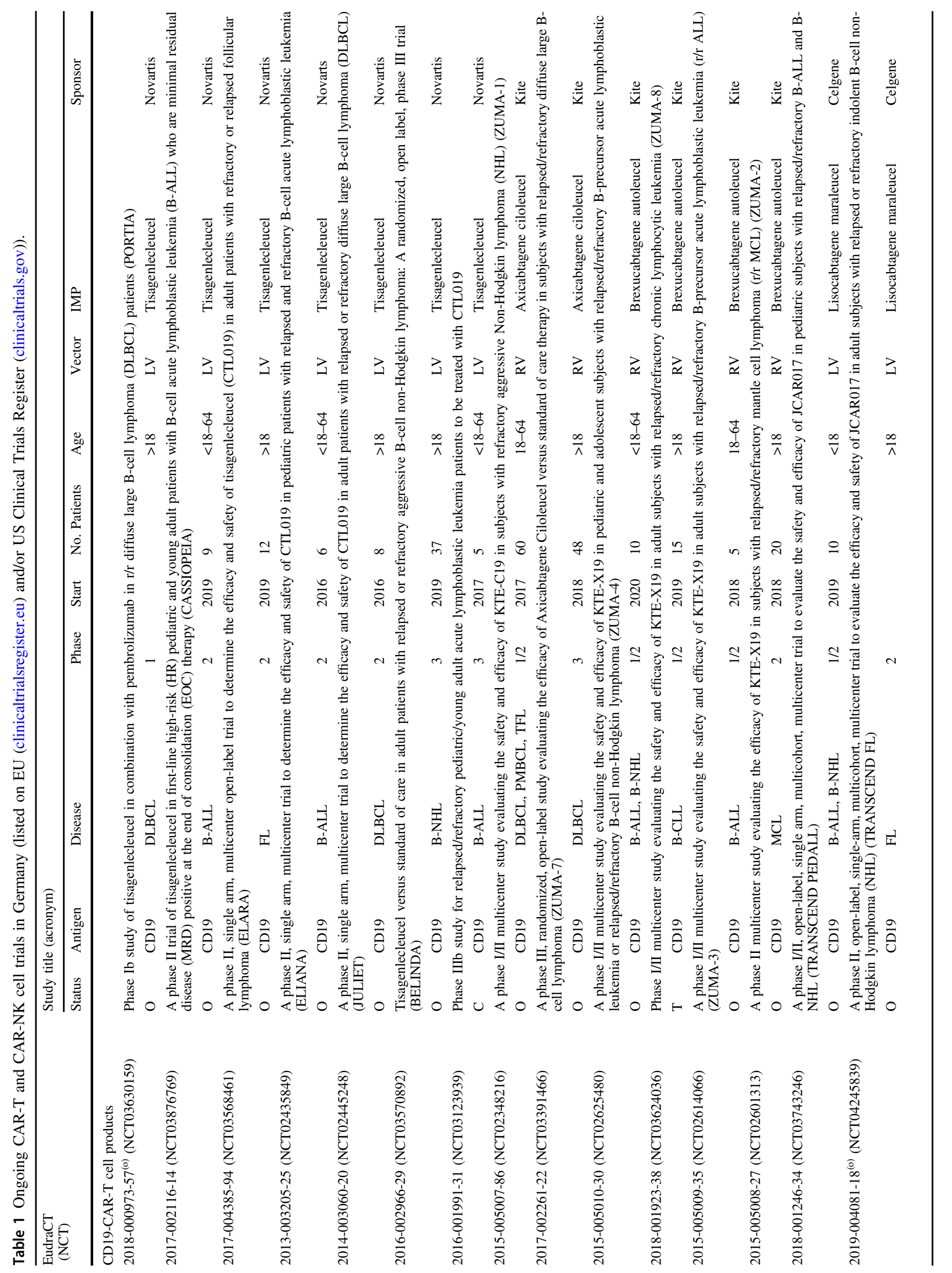




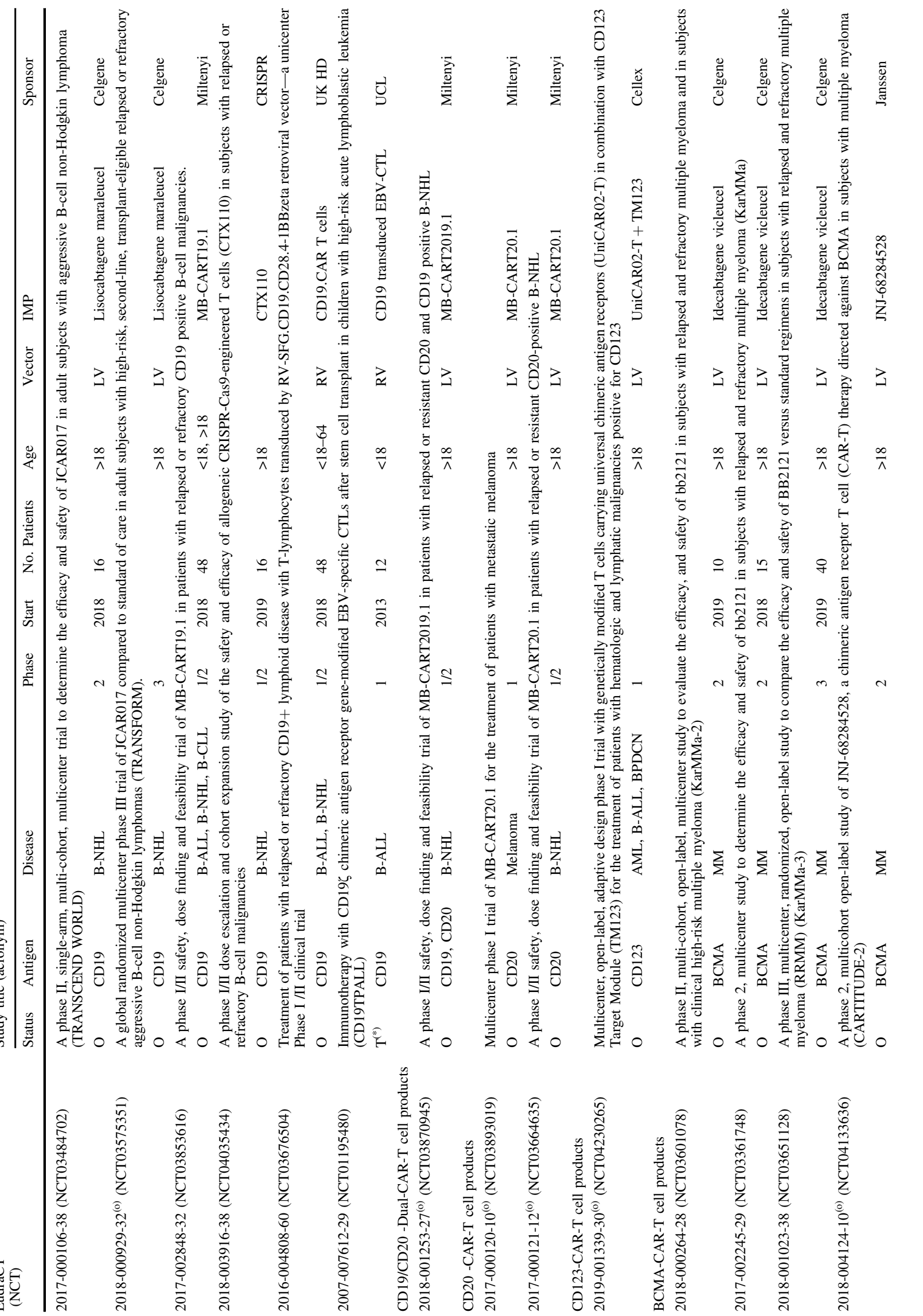




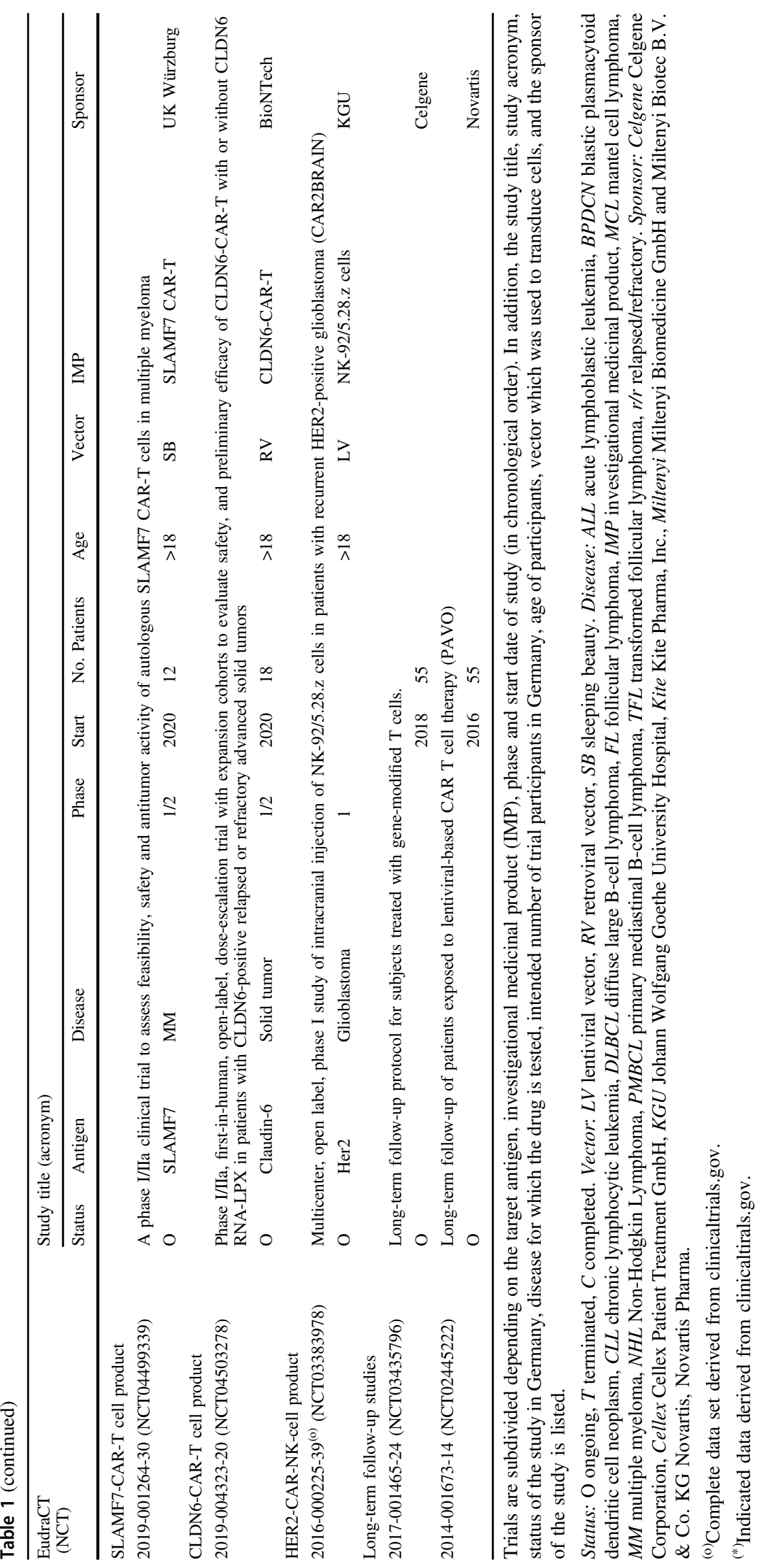


high-risk pediatric and young adult patients with B-ALL at the end of consolidation therapy (ELARA, NCT03568461 and CASSIOPEIA, NCT03876769). In total 12 and 9 patients, respectively, are intended to be treated in Germany. Participating study sites in Germany are located in Cologne, Ulm and Munich for ELARA as well as Frankfurt and Munich for CASSIOPEIA.

In addition, a phase I multicenter study is currently conducted in Cologne, Germany, as well as in Austria, the US and Canada, testing Kymriah in combination with the PD-1 inhibitor Pembrolizumab in a cohort of up to 32 patients suffering from DLBCL (PORTIA, NCT03630159). First results of 4 treated patients showed a manageable safety profile of Pembrolizumab in combination with Kymriah without dose-limiting toxicities or clinical significant exacerbations of adverse events [31].

The LTFU study PAVO (NCT02445222) aims to evaluate the risk of delayed adverse events, check for replication competent lentivirus and estimate long-term efficacy, including CAR-T cell persistence. In this non-interventional study, Novartis monitors up to 1,250 patients for 15 years, who had been exposed to one of the CAR-T cell therapies using Kymriah.

In addition to the above-mentioned trials, 12 ongoing studies investigate Kyrmiah outside Germany.

\section{Yescarta}

The second approved CAR-T cell product to date, is Axicabtagene Ciloleucel (market name Yescarta; lab code KTE-C19 or axi-cel; producer: Kite, a Gilead Science, Inc company). It has received marketing authorization in Europe parallel to Kymriah in August 2018 and just a few months later in the US (October 2018) [32, 33]. For this therapy, patient-derived $\mathrm{T}$ cells are transduced using a gamma-retroviral vector that expresses a second-generation CAR which targets CD19 similar to Kymriah. Thus it possesses a different intracellular co-stimulatory domain derived from CD28 [34]. Notably, Yescarta is generated from $\mathrm{CD}^{+}$enriched autologous $\mathrm{T}$ cells.

Yescarta is authorized as therapy for adult patients with $\mathrm{r} / \mathrm{r}$ DLBCL and primary mediastinal large B-cell lymphoma, after two or more lines of systemic therapy. The key study for approval, partly being conducted in Germany, was the phase II part of the phase I/II multicenter study ZUMA-1 (NCT02348216). In this still ongoing study, the safety and efficacy of Yescarta has been analyzed and the effects of prophylactic regimens or earlier interventions on the abundance and severity of adverse side effects has been evaluated. At the time of marketing authorization application (MAA), data from 111 patients across 24 trial sites were available, demonstrating a higher overall response rate for patients treated with Yescarta compared to the historical control [32, 35, 36]. In total, 307 adult patients are planned to be included, at 37 study locations. Out of these, up to 60 patients are treated in Germany at the university hospitals of Dresden, Essen and Würzburg. Further real-world safety and efficacy data on the use of Yescarta is expected through the expanded access trial ZUMA-9 (NCT03153462) conducted in the US only.

Currently, one further study investigating Yescarta is conducted in Germany. This study is a phase III multicenter study in which Yescarta is compared to standard care therapy in up to 359 patients with $\mathrm{r} / \mathrm{r}$ DLBCL at 77 different study locations (ZUMA-7, NCT03391466). Thereof, 48 patients are planned to be treated at six different study sites in Germany, including the university hospitals of Dresden, Göttingen and Hamburg-Eppendorf.

In addition to the above-mentioned trials, currently 13 ongoing studies are evaluating treatment protocols with Yescarta outside Germany.

\section{Tecartus}

At the beginning of 2020, Kite announced the MAA for its second CAR-T cell product brexucabtagene autoleucel (market name Tecartus ${ }^{\mathrm{TM}}$; lab code KTE-X19 or brexu-cel), which has been currently approved by the FDA (July 2020) and the EC (December 2020) [37, 38]. Notably, Tecartus is a T-cell product similar to Yescarta in terms of generation and CAR structure, but is the first and only CAR-T cell therapeutic for adult patients suffering from $\mathrm{r} / \mathrm{r}$ mantle cell lymphoma (MCL) [39-42]. The clinical safety review by the FDA was primarily based on the analysis of 88 patients that have been treated in the ZUMA-2 study (NCT02601313) [39], which is an ongoing phase II multicenter study for the treatment of $\mathrm{r} / \mathrm{r}$ MCL conducted at various sites in the US and Europe with up to 105 patients in total. In Germany, up to 20 patients are treated at the university hospitals of Dresden and Würzburg. The ZUMA2 clinical trial has already generated impressive results, as 93\% of the patients responded to a single infusion of Tecartus and $67 \%$ attained a complete response $[38,40]$.

Furthermore, Tecartus is currently being tested in four different studies, partly located in Germany, not only for the indication MCL but also for the treatment of B-ALL or BNHL, including chronic lymphocytic leukemia (CLL). In the two phase I/II multicenter studies ZUMA-3 and ZUMA4 (NCT02614066, NCT02625480) over 100 patients, each suffering from $\mathrm{r} / \mathrm{r}$ B-ALL or B-NHL will be treated with Tecartus. The study locations are distributed all over the US and Europe. In Germany, five (ZUMA-3) and ten patients (ZUMA-4) are intended to be treated in at least three different study sites (Frankfurt, Munich, Würzburg).

Moreover, Tecartus is also being tested for patients with $\mathrm{r} / \mathrm{r}$ B-CLL in one phase I/II multicenter study (ZUMA-8, 
NCT03624036). It is currently ongoing at 21 different study locations in the US. It was planned to conduct the trial in Germany as well, but it was prematurely ended.

\section{JCAR017}

Celgene, as part of the US biotech company Bristol-Myers Squibb $^{\mathrm{TM}}$, initiated its first clinical trial in Germany in 2016 with the second-generation CAR-T cell product JCAR015 (NCT02973191). However, this study was withdrawn owing to the development of cerebral edema and subsequent death of several B-ALL-patients, who had participated in the phase II ROCKET trial (NCT02535364) [43-47]. Subsequently, Celgene proceeded with JCAR017 as therapy for $\mathrm{r} / \mathrm{r}$ DLBCL, another CAR-T cell product, which possesses an improved safety profile compared to JCAR015 [43, 46]. While cells used to create JCAR015 were composed of $\mathrm{CD}^{+}$enriched PBMCs, which were transduced using a gamma-retroviral vector, in JCAR017, a fixed ratio of $\mathrm{CD}^{+}$and $\mathrm{CD} 8^{+}$cells (1:1) is transduced using lentiviral vectors [48]. Additionally, Celgene changed the CD19-specific scFv-based binding domain and co-stimulatory domain from $\mathrm{SJ} 25 \mathrm{C} 1$ to FMC63 and CD28 to 4-1BB in JCAR017, respectively. Furthermore, they included a truncated version of the human epidermal growth factor receptor (EGFRt) in JCAR017, which might offer the potential to induce killing of CAR-T cells following addition of cetuximab (Erbitux ${ }^{\circ}$ ) [43, 46]. Taking these changes into consideration, their new product JCAR017 already showed promising results in their TRANSCEND NHL 001 trial in patients with $\mathrm{r} / \mathrm{r}$ pediatric B-ALL and B-NHL (NCT02631044) [48]. Based on these findings, Bristol-Myers Squibb recently submitted the product JCAR017 (international nonproprietary name Lisocabtagene maraleucel; market name Breyanzi ${ }^{(\mathrm{R})}$ lab code liso-cel) for authorization in the US and Europe [49, 50] and just recieved approval in the US [18].

Currently, there are nine ongoing clinical trials worldwide which use JCAR017. Of these, four are conducted in Germany. The most advanced trial is the multicenter phase III study TRANSFORM, that will include 182 adult patients with high-risk, aggressive r/r B-NHL (NCT03575351). Patients are being treated at 53 study locations in the US and Europe including six study sites in Germany, e.g., the university hospitals of Dresden, Cologne and Munich. Additionally, JCAR017 is deployed in the multicenter phase II study TRANSCEND WORLD, which will contain 116 participants suffering from similar diseases (NCT03484702). This study is being conducted at 19 different study sites across Europe with 16 patients scheduled to be treated in five centers in Germany, such as the university hospitals of Heidelberg, Cologne and Munich.

In the phase II multicenter study TRANSCEND FL, JCAR017 will be tested in 188 patients with $\mathrm{r} / \mathrm{r}$ indolent
B-NHL (NCT04245839). Patients will be treated in 36 study locations all around the world including study sites in Germany Cologne, Munich and Ulm. Furthermore, one phase I/II multicenter study with JCAR017 is being conducted (NCT03743246). This study will comprise 121 pediatric patients suffering from $\mathrm{r} / \mathrm{r}$ B-ALL and B-NHL. Out of these patients, ten are going to be treated in Germany.

Similar to Novartis, Celgene is also conducting a LTFU study with patients who had received a gene-modified ' $T$ cell therapy sponsored by Celgene or alliance partners (NCT03435796). In this study, patients will be monitored over 15 years for long-term safety and efficacy following the last CAR-T cell infusion.

\section{MB-CART19.1}

In the field of $\mathrm{CD} 19^{+}$malignancies the German company Miltenyi Biotec has also developed a CD19-targeting T-cell product called $M B-C A R T 19.1$. It is generated by transduction of autologous $\mathrm{CD}^{+} / \mathrm{CD}^{+}$enriched $\mathrm{T}$ cells using a lentiviral vector encoding a second-generation $\mathrm{CAR}$ which harbors 4-1BB as co-stimulatory domain [51, 52]. MBCART.19.1 is currently being tested in one clinical trial in Germany only. This phase I/II multicenter study will include up to 48 pediatric and adult participants suffering from $\mathrm{r} / \mathrm{r} \mathrm{CD} 19^{+} \mathrm{B}$-cell malignancies such as B-ALL, BCLL, and B-NHL (NCT03853616) at the sites Erlangen and Muenster.

\section{CTX110}

While most companies use autologous enriched $\mathrm{T}$ cells to avoid graft-versus-host disease (GvHD) and viral vectors for transduction, some companies envision new approaches such as the Swiss company CRISPR Therapeutics that is specialized in gene editing using the clustered regularly interspaced short palindromic repeats (CRISPR)/Cas9 technology.

CRISPR Therapeutics' T-cell product CTX110 consists of allogeneic derived $\mathrm{T}$ cells which are ex vivo edited by use of the CRISPR/Cas9 technology to insert the CARconstruct precisely into the TCR alpha constant (TRAC) locus and simultaneously disrupt endogenous T-cell expression to reduce the risk of GvHD. In addition, to improve CAR-T cell persistence, major histocompatibility complex expression is eliminated to avoid rejection of the allogeneic CAR-T cell product by the patient's own immune cells [53]. The idea behind this concept is to generate off-the-shelf CAR-T cell products which is very appealing to circumvent hurdles associated with the complex manufacturing process of autologous CAR-T cell therapies [11]. Currently, CTX110 is being tested in one 
phase I/II multicenter study with 95 patients suffering from $\mathrm{r} / \mathrm{r}$ B-cell malignancies such as B-NHL or B-cell lymphoma (NCT04035434). Out of these patients, 16 are planned to be treated in Hamburg, Germany.

Besides CTX110, CRISPR Therapeutics currently also develops allogeneic CAR-T cell product for the treatment of r/r MM (CTX120, NCT04244656) and solid tumors (CTX130, NCT04438083).

\section{Other CD19-specific CAR-T cell products}

Not only do companies draft clinical trials using CD19targeting CAR-T cell therapies, but also investigator-driven clinical studies are performed, such as the CD19.CAR T trial at the university hospital of Heidelberg. This trial deploys autologous $\mathrm{T}$ cells which are retrovirally transduced to express a third generation CAR which possesses the intracellular co-stimulatory domains derived from CD28 and 41BB. In this phase I/II study, 48 adult patients suffering from r/r B-ALL, B-NHL, B-CLL, DLBCL, FL, or MCL will be treated with escalating doses of CD19.CAR T cells (NCT03676504). It has been reported so far that patients treated with CD19.CAR T cells responded clinically, despite the administration of low cell numbers. Injected CAR-T cells showed a very good safety profile, were detectable in the body for over 3 months post administration and were able to migrate into different compartments [54].

Furthermore, a clinical trial evaluating the feasibility, safety and biological effect of adoptive transfer of donorderived EBV-specific cytotoxic T-lymphocytes (EBV-CTL) transduced with a gamma-retroviral vector encoding a first generation CD19-specific CAR construct for the treatment of patients with high-risk or relapsed B-cell precursor ALL after allogeneic hematopoietic stem cell transplantation was conducted in Germany and the UK (NCT01195480). This trial intended to include up to 12 patients in Germany but was terminated due to the lack of biological efficacy and CAR-T cell persistence as reported at clinicaltrials.gov.

\section{MB-CART20.1 and MB-CART2019.1}

In order to treat B-cell malignancies, not only CD19 but also CD20 seems to be a very suitable target, as it is tightly restricted and expressed on most $\mathrm{B}$ cells starting early in the pre-B stage of B-cell ontogeny. Owing to the fact that it is absent on precursor lymphoid cells and majority of plasma cells, killing of $\mathrm{CD} 20^{+}$cells should not disrupt monoclonal antibody $(\mathrm{mAb})$ production and also maintain B-cell regeneration post therapy $[55,56]$.

Hence, Miltenyi Biotec developed two different CD20targeting T-cell products, generated from autologous $\mathrm{CD} 4^{+} / \mathrm{CD} 8^{+}$enriched $\mathrm{T}$ cells transduced, using a lentiviral vector. One is called MB-CART20.1 and consists of T cells expressing a second-generation CD20-specific CAR harboring the 4-1BB co-stimulatory domain. This product is currently being tested in two studies exclusively in Germany. In the phase I/II dose-finding study, 19 patients suffering from $\mathrm{CD}_{2} 0^{+} \mathrm{r} / \mathrm{r}$ B-NHL are intended to be included at the university hospitals of Cologne and Leipzig (NCT03664635). The second trial investigates the usage of MB-CART20.1 for the treatment of unresectable stage III or IV melanoma in up to 15 patients in an earl phase I multicenter study at the University Hospital Cologne (NCT03893019). Notably, this is the first trial with CD20CAR transduced $\mathrm{T}$ cells against melanoma conducted in Europe and is based on findings that melanoma cancer sustaining cells express CD20 [57, 58].

The other $\mathrm{T}$ cell product by Miltenyi Biotec, MBCART2019.1, comprises T cells engineered to express tandem CAR constructs targeting both CD19 and CD20. This approach offers the potential to prevent emergence of antigen escape and was shown to be more effective and less toxic in a higher disease burden setting in a preclinical model [59, 60]. Currently MB-CART2019.1 is being tested in one multicenter phase I/II dose-finding trial in Germany with up to 12 adult patients suffering from $\mathrm{r} / \mathrm{r}$, aggressive CD19- and CD20-positive B-NHL/CLL or B-cell small lymphocytic lymphoma (B-SLL) (NCT03870945). Study sites include the university hospitals of Cologne, HamburgEppendorf and Augsburg.

\section{CAR-T cells targeting AML}

While most CAR-T cell therapies are designed to target Bcell malignancies, they are also under development for the treatment of different hematologic diseases such as AML. Besides CD33, which was detected on AML blasts in $85-90 \%$ of patients and shown to be present on leukemic stem cells (LCSs), also CD123 expression could be detected on AML blasts as well as LCSs in 75-89\% of cases [61-64]. Thus, both antigens were evaluated as promising targets for AML-specific CAR-cellular therapies. In line with these findings, the German company Cellex Patient Treatment $\mathrm{GmbH}$ created a modular universal CAR platform called UniCAR, to generate adapter CARs which consists of two components: a targeting module (TM)-specific CAR for the initial T-cell engineering and a TM which redirects the UniCAR-T cells to a specific target (e.g., a CD33 or CD123 antigen on AML blasts). This system was designed to easily change targets of CAR-T cells by simply replacing the TMs. Applications include targeting of more than one antigen simultaneously, consecutive addition of different TMs to enhance therapy efficacy and to reduce the risk of antigenloss tumor variants during the treatment [65-67].

Currently the study drug UniCAR02-T-CD123 is tested for its safety and efficacy in one dose-escalating multicenter 
phase I trial (NCT04230265) which is conducted in Germany. UniCAR02-T-CD123 consist of the cellular component UniCAR02-T and a recombinant antibody derivative targeting CD123 (TM123). The study will comprise 45 participants with hematologic and lymphatic malignancies such as AML, B-ALL, and blastic plasmacytoid dendritic cell neoplasm positive for CD123. The patients will be treated in five study sites in Germany, including the university hospitals of Würzburg and Dresden.

\section{CAR-T cells for the treatment of multiple myeloma}

Another disease with unmet medical needs is MM. It is a progressive, usually incurable disease, probably resulting from multiple genetic mutations to the precursor plasma cell. All MM cells express the B-cell maturation antigen (BCMA), a transmembrane glycoprotein in the TNF receptor superfamily 17 (TNFRSF17), which is not expressed on other normal tissues except on normal plasma cells and was demonstrated to be a suitable target for CAR-T cell therapy [68]. In this line, BCMA-specific CAR-T cells have demonstrated clinical response in patients with $\mathrm{r} / \mathrm{r} \mathrm{MM}$, that have undergone at least three prior treatments [69].

The most advanced BCMA-CAR-T cell product for the treatment of $\mathrm{r} / \mathrm{r} \mathrm{MM}$ is idecabtagene vicleucel (lab code idecel, bb2121), an investigational BCMA-specific CAR-T cell therapy developed by the US pharma company Brystol Myers Squibb (former company: Celgene), which is currently under evaluation in the US and Europe to receive marketing authorization [70, 71]. Ide-cel consists of autologous $\mathrm{T}$ cells transduced with a lentiviral vector to express a BCMA-specific second-generation CAR, which possess $4-1 \mathrm{BB}$ as intracellular co-stimulatory domain $[72,73]$. The MAA is based on the results derived from the pivotal phase 2 KarMMa study evaluating the efficacy and safety of idecel in heavily pre-treated patients with relapsed and refractory MM (NCT03361748) [71]. In this ongoing study up to 149 patients at 24 study locations worldwide will be investigated. Out of these, 15 patients are scheduled to be treated in Germany at the university hospitals of Würzburg, Heidelberg and Tübingen. Initial results of 128 treated patients demonstrated deep, durable responses of ide-cel with an overall response rate of $73 \%$ and a favorable clinical benefit-risk profile across the target dose range [74].

Furthermore, ide-cel is currently being tested in five different studies for the treatment of $\mathrm{r} / \mathrm{r}$ or high-risk MM which are partly located in Germany. In the KarMMa-2 study (NCT03601078), a phase II multicenter trial evaluating the safety and efficacy of ide-cel in high-risk MM patients, up to 181 participants will be included across 26 study locations in the US and Europe. In Germany ten patients are scheduled to be treated at the university hospitals of Würzburg, Hamburg and Tübingen. In the phase III multicenter trial KarMMA-3 ide-cel will be compared to standard of care treatment in up to 381 participants at 49 different study sites located all over the world (NCT03651128). Thereof, 40 patients are planned to be treated in Germany at the university hospitals of Würzburg, Heidelberg and Cologne.

In addition to Brystol Myers Squibbs' ide-cel, also the US pharma company Janssen Pharmaceutica (part of Johnson \& Johnson) is testing the BCMA-targeting CAR-T cell therapeutic JNJ-68284528 in Germany. CAR-T cells in JNJ68284528 possess two BCMA-targeting single-domain antibodies designed to enable avidity of the CAR construct towards BCMA [75]. In its phase II trial CARTITUDE-2, JNJ-68284528 is going to be applied to 100 patients suffering from MM (NCT04133636). The trial sites are located in the US, Israel and Europe and include the University hospitals of Würzburg, Heidelberg and Hamburg-Eppendorf in Germany. Notably, the efficacy of JNJ-68284528 is currently addressed in two more trials for the treatment of MM without the contribution of German trial sites.

Another antigen which is currently under evaluation for CAR-T cell therapy in patients with MM is SLAMF7 (signaling lymphocytic activation molecule F7, also known as CS1). SLAMF7 was shown to be highly expressed on malignant plasma cells in $\mathrm{MM}$ and has functional significance [76]. In the ongoing phase I/II clinical trial CARAMBA-1 (NCT04499339) conducted by the University Hospital Würzburg, the safety, feasibility and antitumor activity of autologous SLAMF7-specific CAR-T cells is tested in up to 38 patients suffering from MM. The patients will be treated at the trial sites Würzburg, Germany; Pamplona, Spain; Milano, Italy and Lile, France. SLAMF7specific CAR-T cells in this study are generated by the Sleeping Beauty Transposon gene transfer. This constitutes an alternative virus-free method with the aim to increase the safety and reduce the production costs of manufactured CAR-T cells [77]. This project started in January 2018 and is funded by the EU Horizon 2020 program $[78,79]$.

\section{Claudin-6 (CLDN6) CAR-T cells to fight solid tumors}

Although CAR-T cells appear to be very effective in targeting hematological diseases, many challenges still exist for the usage of CAR-T cells to treat solid tumors. These are for instance the immune-suppressive effects of the tumor microenvironment, the trafficking of CAR-T cells to the tumor site and tumor infiltration as well as the lack of cancer-specific solid tumor targets to reduce severe on-target/off-tumor toxicities [80].

Nevertheless, academia and companies are trying to employ CAR-T cells for the treatment of solid tumors such as the German company BioNTech Cell \& Gene Therapies $\mathrm{GmbH}$. Their CAR-T cell product BNT211 consists of 
autologous $\mathrm{T}$ cells equipped with a second-generation CAR specific for the tight junction protein Claudin-6 (CLDN6) that will be administered in combination with a $\underline{C} A R-T$ cell amplifying RNA Vaccine (CARVac) to drive expansion, persistence and efficacy of the CLDN6-CAR-T cells against solid tumors [81, 82]. CARVac is derived from BioNTech's proprietary RNA lipoplex (RNA-LPX) technology tailormade for body-wide delivery of antigen to lymphatic tissue upon systemic administration [83]. Importantly, RNA-LPX is being used in numerous clinical trials for induction of endogenous T-cell responses against a plethora of cancer antigens (e.g., NCT02410733, NCT02316457, and NCT03815058). In its first phase I/II multicenter cell therapy study, BioNTech wants to evaluate the safety and efficacy of BNT211 in patients with $\mathrm{CLDN6}^{+} \mathrm{r} / \mathrm{r}$ advanced solid tumors such as ovarian, testicular, uterine, lung and gastric cancer (NCT04503278).

\section{CAR-NK cell therapies}

NK cells have recently moved into the spotlight as an imposing tool for immunotherapy. While NK cells utilize similar killing mechanisms for eliminating malignant or virally infected cells compared to cytotoxic T-lymphocytes (CTLs), their target recognition mechanism differs substantially. CTLs as part of the adaptive immune response, recognize their targets via a vast variety of clonally rearranged T-cell receptors (TCRs). NK cells on the other hand, as innate lymphoid cells, receive activating and inhibitory signals by their germline-encoded receptor repertoire [84]. The ability to recognize the absence of HLA-proteins, specializes NK cells to identify malignant or virally infected cells, which often downregulate these proteins to escape immune surveillance [22]. Thus, a CAR-NK cell therapy could offer the advantage of an intrinsic tumor killing capacity possessed by CAR-NK cells in addition to their CAR-depended killing mechanism, impeding tumor immune escape mechanisms. Furthermore, the absence of TCRs strongly reduces the risk of GvHD, which potentially could enable allogeneic CAR-NK cell transplantations [19-21, 85]. The latter could reduce the tremendous costs required as well as the limited availability of an autologous therapy, which is caused by logistics and the low cell numbers of often heavily pre-treated patients $[11,86]$.

CAR-NK cell therapies have been evaluated lately in different tumor settings. Quite recently, the group of Katy Rezvani published clinical results of the first 11 patients receiving CAR-NK cells derived from umbilical cord blood (UCB) for targeting CD19-expressing B-cell malignancies (NCT03056339). Eight out of these 11 patients showed a clinical response $(73 \%)$. Of these patients, seven had complete remission and the responses were rapid [86]. This and other trials indicate that CAR-NK cells might represent a promising therapeutic option with the above-mentioned beneficial properties.

\section{HER2-specifc CAR-NK cells for the treatment of glioblastoma}

Therapies involving primary NK cell preparations are faced with hurdles, such as the challenging viral transduction, and the still cost- and time-intensive expansion of primary NK cells under good manufacturing practice (GMP) conditions [87]. Hence, the first and currently only ongoing clinical trial with CAR-NK cells in Germany deploys glioblastomaspecific CAR-NK-92 cells (CAR2BRAIN, NCT03383978) [88]. NK-92 is the only human NK cell line to date approved for the treatment of patients in clinical trials $[89,90]$. NK-92 cells hold the advantage of being easily expandable under GMP conditions, and display features of activated NK cells with high antitumor efficacy due to the lack of most inhibitory NK cell receptors [89, 91, 92]. Nevertheless, NK-92 cells also face critical obstacles such as the requirement for irradiation to reduce their proliferative capacity, as they are derived from a lymphoma [93]. Additionally, NK-92 cells are IL-2 dependent, which could result in toxicities if repeated IL-2 injections are combined with cellular therapy [93-96]. In the phase I clinical trial CAR2BRAIN, intrathecal administration of genetically engineered NK-92/5.28.z cells during relapse surgery is being tested at the University Hospital Frankfurt in patients suffering from recurrent HER $2^{+}$glioblastoma (GB) [88]. This cell product consists of lentivirally transduced NK92 cells expressing a human epidermal growth factor 2 (HER2, ErbB2)-specific second-generation CAR, which harbors a composite $\mathrm{CD} 3 \zeta-\mathrm{CD} 28$ signaling moiety [97]. The single-dose dose-escalation part of the study has recently been completed, without encountering dose-limiting toxicities at the three applied dose levels. Currently, patients of the expansion cohort of the trial are being recruited, scheduled to receive repeated weekly injections of irradiated NK-92/5.28.z cells into the resection cavity through an implanted catheter and reservoir [88]. HER2 was chosen as target, as it was found to be expressed by about $40 \%$ of primary GB cells and the majority of GB cell lines. An effective therapy is urgently needed, as GBM is the most common and aggressive primary brain cancer, with low 5-year overall survival rates following standard of care therapy including surgical resection and adjuvant chemotherapy [97, 98].

\section{Future perspective of CAR-T and CAR-NK studies}

The field of CAR-cellular therapies is still young, but preclinical and clinical studies have already shown remarkable 
results. To date the first four drugs in the US and three in Europe have so far been granted marketing authorization, using CAR-modified immune cells as therapies for specific hematological malignancies. Thus, a multitude of targets have yet to be addressed, with even considering nonmalignant targets such as HIV-infected cells [99, 100]. In this context, it is important to keep in mind that adjustments can be made regarding the CAR structure, additional genetic modifications and the choice of the adoptive immune cells. The combination of cellular therapies with other drugs such as immune-checkpoint inhibitors could further improve clinical outcomes. Therefore, we believe that the field of CAR-based cellular therapies is profoundly promising and is certainly going to lead to the development of approved personalized therapeutic options in the future.

Acknowledgements We thank Winfried Wels, Michael Hudecek, Katy Rezvani, Michael Schmitt, Peter Bader, Andreas Mackensen, Sebastian Kreiter, Benjamin Rengstl, Özlem Türeci, and Ugur Sahin for personal communication and discussion of yet unpublished data from their ongoing clinical trials and we apologize to all investigators whose work was not cited in this article due to space limitations.

Funding The laboratory of EU has been supported by the FCI and DKTK (to EU), by the DFG (CRC/SFB 1292 and IRTG; to EU and NA), by the German Cancer Aid (to EU), the "Alfred \& Angelika Gutermuth-Stiftung" (to EU), and by "Menschen für Kinder e.V." (to EU). Open Access funding enabled and organized by Projekt DEAL.

\section{Compliance with ethical standards}

Conflict of interest The authors declare no competing interests.

Publisher's note Springer Nature remains neutral with regard to jurisdictional claims in published maps and institutional affiliations.

Open Access This article is licensed under a Creative Commons Attribution 4.0 International License, which permits use, sharing, adaptation, distribution and reproduction in any medium or format, as long as you give appropriate credit to the original author(s) and the source, provide a link to the Creative Commons license, and indicate if changes were made. The images or other third party material in this article are included in the article's Creative Commons license, unless indicated otherwise in a credit line to the material. If material is not included in the article's Creative Commons license and your intended use is not permitted by statutory regulation or exceeds the permitted use, you will need to obtain permission directly from the copyright holder. To view a copy of this license, visit http://creativecommons. org/licenses/by/4.0/.

\section{References}

1. DeVita VT, Chu E. A history of cancer chemotherapy. Cancer Res. 2008;68:8643-53.

2. Maude SL, Teachey DT, Porter DL, Grupp SA. CD19-targeted chimeric antigen receptor T-cell therapy for acute lymphoblastic leukemia. Blood. 2015;125:4017-23.
3. Hartmann J, Schüßler-Lenz M, Bondanza A, Buchholz CJ. Clinical development of CAR T cells-challenges and opportunities in translating innovative treatment concepts. EMBO Mol Med. 2017;9:1183-97.

4. Zhylko A, Winiarska M, Graczyk-Jarzynka A. The great war of today: modifications of CAR-T cells to effectively combat malignancies. Cancers. 2020;12:2030.

5. You F, Wang Y, Jiang L, Zhu X, Chen D, Yuan L, et al. A novel CD7 chimeric antigen receptor-modified NK-92MI cell line targeting T-cell acute lymphoblastic leukemia. Am J Cancer Res. 2019;9:64-78.

6. Duan H, Huang H, Jing G. An antibody fab fragment-based chimeric antigen receptor could efficiently eliminate human thyroid cancer cells. J Cancer. 2019;10:1890-5.

7. Balakrishnan A, Rajan A, Salter AI, Kosasih PL, Wu Q, Voutsinas J, et al. Multispecific targeting with synthetic ankyrin repeat motif chimeric antigen receptors. Clin Cancer Res. 2019; 25:7506-16.

8. Grote S, Seitz CM, Diepold S, Buchner M, Baden C, Malenke E, et al. Adapter chimeric antigen receptor (aCAR)-engineered NK92 cells: an off-the-shelf cellular therapeutic for universal tumor targeting. Blood. 2018;132 Supplement 1:3331.

9. Lee YG, Marks I, Srinivasarao M, Kanduluru AK, Mahalingam $\mathrm{SM}$, Liu X, et al. Use of a single CAR $\mathrm{T}$ cell and several bispecific adapters facilitates eradication of multiple antigenically different solid tumors. Cancer Res. 2019;79:387-96.

10. Neelapu SS. CAR-T efficacy: is conditioning the key? Blood. 2019;133:1799-800.

11. Depil S, Duchateau P, Grupp SA, Mufti G, Poirot L. 'Off-theshelf' allogeneic CAR T cells: development and challenges. Nat Rev Drug Discov. 2020;19:185-99.

12. Reindl LM, Albinger N, Bexte T, Müller S, Hartmann J, Ullrich E. Immunotherapy with NK cells: recent developments in gene modification open up new avenues. Oncoimmunology. 2020;9:1-12.

13. Müller S, Bexte T, Gebel V, Kalensee F, Stolzenberg E, Hartmann $\mathrm{J}$, et al. High cytotoxic efficiency of lentivirally and alpharetrovirally engineered CD19-specific chimeric antigen receptor natural killer cells against acute lymphoblastic leukemia. Front Immunol. 2019;10:3123.

14. Jamali A, Hadjati J, Madjd Z, Mirzaei HR, Thalheimer FB, Agarwal S, et al. Highly efficient generation of transgenically augmented CAR NK cells overexpressing CXCR4. Front Immunol. 2020;11:2028. https://www.frontiersin.org/article/10. 3389/fimmu.2020.02028.

15. Detela G, Lodge AEU. Regulatory pathways for ATMPs: standard, accelerated and adaptive pathways to marketing authorisation. Mol Ther Methods Clin Dev. 2019;13:205-32.

16. Gilead Sciences I. U.S. FDA Approves Kite's Tecartus ${ }^{\mathrm{TM}}$, the first and only CAR T treatment for relapsed or refractory mantle cell lymphoma. 2020. https://www.gilead.com/news-and-press/ press-room/press-releases/2020/7/us-fda-approves-kites-tecartusthe-first-and-only-car-t-treatment-for-relapsed-or-refractory-ma ntle-cell-lymphoma.

17. Gilead Sciences I. Kite's Tecartus ${ }^{\mathrm{TM}}$ (KTE-X19) Granted Conditional Marketing Authorization for the Treatment of Relapsed or Refractory Mantle Cell Lymphoma in Europe. 2020. https://www.gilead.com/news-and-press/press-room/press-relea ses/2020/12/kites-tecartus-ktex 19-granted-conditional-ma rketing-authorization-for-the-treatment-of-relapsed-or-refractorymantle-cell-lymphoma-in-europe.

18. Bristol Myers Squibb. U.S. Food and Drug Administration Approves Bristol Myers Squibb's Breyanzi (lisocabtagene maraleucel), a New CAR T Cell Therapy for Adults with Relapsed or Refractory Large B-cell Lymphoma. 2021. https://news.bms. com/news/details/2021/U.S.-Food-and-Drug-Administration- 
Approves-Bristol-Myers-Squibbs-Breyanzi-lisocabtagene-mara leucel-a-New-CAR-T-Cell-Therapy-for-Adults-with-Relapsedor-Refractory-Large-B-cell-Lymphoma/default.aspx.

19. Moretta L, Locatelli F, Pende D, Marcenaro E, Mingari MC, Moretta A. Killer Ig-like receptor-mediated control of natural killer cell alloreactivity in haploidentical hematopoietic stem cell transplantation. Blood. 2011;117:764-71.

20. Rubnitz JE, Inaba $\mathrm{H}$, Ribeiro RC, Pounds S, Rooney B, Bell T, et al. NKAML: a pilot study to determine the safety and feasibility of haploidentical natural killer cell transplantation in childhood acute myeloid leukemia. J Clin Oncol. 2010;28: 955-9.

21. Yoon SR, Lee YS, Yang SH, Ahn KH, Lee J-H, Lee J-H, et al. Generation of donor natural killer cells from $\mathrm{CD} 34(+)$ progenitor cells and subsequent infusion after HLA-mismatched allogeneic hematopoietic cell transplantation: a feasibility study. Bone Marrow Transplant. 2010;45:1038-46.

22. Freeman AJ, Vervoort SJ, Ramsbottom KM, Kelly MJ, Michie J, Pijpers L, et al. Natural killer cells suppress T cell-associated tumor immune evasion. Cell Rep. 2019;28:2784-94.e5.

23. Makita S, Yoshimura K, Tobinai K. Clinical development of anti-CD19 chimeric antigen receptor T-cell therapy for B-cell non-Hodgkin lymphoma. Cancer Sci. 2017;108:1109-18. https:// pubmed.ncbi.nlm.nih.gov/28301076.

24. Scheuermann RH, Racila E. CD19 Antigen in leukemia and lymphoma diagnosis and immunotherapy. Leuk Lymphoma. 1995;18:385-97.

25. U.S. Food \& Drug Administrations. KYMRIAH (tisagenlecleucel). https://www.fda.gov/vaccines-blood-biologics/cellular-genetherapy-products/kymriah-tisagenlecleucel.

26. European Medicines Agency. Kymriah. 2020. https://www.ema. europa.eu/en/medicines/human/EPAR/kymriah.

27. Pharmaceutical Technology. Norvatis receives EC approval for Kymriah to treat two cancers. 2018. https://www.pharmaceutica 1-technology.com/news/novartis-european-commissions-approva 1-kymriah/\#: :text=The\%20European $\% 20$ Commission $\% 20$ (EC)\%20has, \%2Dcell\%20lymphoma\%20(DLBCL).

28. Ali S, Kjeken R, Niederlaender C, Markey G, Saunders TS, Opsata M, et al. The European Medicines agency review of Kymriah (Tisagenlecleucel) for the treatment of acute lymphoblastic leukemia and diffuse large B-cell lymphoma. Oncologist. 2020;25:e321-7.

29. Maude SL, Frey N, Shaw PA, Aplenc R, Barrett DM, Bunin NJ, et al. Chimeric antigen receptor $\mathrm{T}$ cells for sustained remissions in leukemia. N Engl J Med. 2014;371:1507-17. https://pubmed. ncbi.nlm.nih.gov/25317870.

30. Krueger J, Bittencourt HNS, Rives S, Baruchel A, Moerloose B de, Peters C, et al. Tisagenlecleucel (Tisa) for relapsed/refractory $(\mathrm{r} / \mathrm{r})$ acute lymphoblastic leukemia (ALL): B2001X study focusing on prior exposure to blinatumomab (BLINA) and inotuzumab (INO). J Clin Oncol. 2020;38:10518.

31. Jaeger U, Worel N, McGuirk JP, Riedell PA, Fleury I, Borchmann P, et al. Abstract CT162: the phase 1b PORTIA study: Safety and efficacy of tisagenlecleucel plus pembrolizumab in patients with relapsed/refractory diffuse large B-cell lymphoma (r/r DLBCL). Cancer Res. 2020;80 16 Supplement:CT162.

32. European Medicines Agency. Yescarta. 2020. https://www.ema. europa.eu/en/medicines/human/EPAR/yescarta.

33. U.S. Food \& Drug Administrations. Yescarta (axicabtagene ciloleucel). 2020. https://www.fda.gov/vaccines-blood-biologics/ cellular-gene-therapy-products/yescarta-axicabtagene-ciloleucel.

34. Jain MD, Bachmeier CA, Phuoc VH, Chavez JC. Axicabtagene ciloleucel (KTE-C19), an anti-CD19 CAR T therapy for the treatment of relapsed/refractory aggressive B-cell non-Hodgkin's lymphoma. Ther Clin Risk Manag. 2018;14:1007-17.
35. Locke FL, Bartlett NL, Jacobson CA, Oluwole OO, Munoz J, Lekakis LJ, et al. Retreatment (reTx) of patients (pts) with refractory large B-cell lymphoma with axicabtagene ciloleucel (axi-cel) in ZUMA-1. J Clin Oncol. 2020;38 15_suppl:8012.

36. Papadouli I, Mueller-Berghaus J, Beuneu C, Ali S, Hofner B, Petavy F, et al. EMA Review of Axicabtagene Ciloleucel (Yescarta) for the Treatment of Diffuse Large B-Cell Lymphoma. Oncologist. 2020;25:894-902.

37. Kite aGC. European Medicines Agency validates kite's marketing application for company's second CAR T cell therapy. 2020. https://www.gilead.com/news-and-press/press-room/pressreleases/2020/1/european-medicines-agency-validates-kites-ma rketing-application-for-companys-second-car-t-cell-therapy.

38. Kite aGC. U.S. FDA grants priority review for Kite's KTE-X19 biologics license application (BLA) in relapsed or refractory mantle cell lymphoma:-If Approved, Kite could be first company with multiple commercialized CAR T therapies. 2020. https://www. businesswire.com/news/home/20200210005203/en/.

39. U.S. Food \& Drug Administrations. TECARTUS (brexucabtagene autoleucel). 2020. https://www.fda.gov/vaccinesblood-biologics/cellular-gene-therapy-products/tecartus-brexuca btagene-autoleucel.

40. Wang M, Munoz J, Goy A, Locke FL, Jacobson CA, Hill BT, et al. KTE-X19 CAR T-cell therapy in relapsed or refractory mantle-cell lymphoma. N Engl J Med. 2020;382:1331-42.

41. Shah BD, Bishop MR, Oluwole OO, Logan A, Baer MR, Donnellan WB, et al. End of phase I results of ZUMA-3, a phase $1 / 2$ study of KTE-X19, anti-CD19 chimeric antigen receptor (CAR) $\mathrm{T}$ cell therapy, in adult patients (pts) with relapsed/ refractory (R/R) acute lymphoblastic leukemia (ALL). J Clin Oncol. 2019;37 15_suppl:7006.

42. European Medicines Agency. EU/3/19/2220. 2020. https://www. ema.europa.eu/en/medicines/human/orphan-designations/ eu3192220.

43. Joseph Gulfo. Juno advances CAR T-cell CAR017 and Halts CAR015 in Non-Hodgkin Lymphoma. 2017. http://blogs.shu. edu/cancer/2017/03/08/juno-advances-car-t-cell-car017-and-ha lts-car015-in-non-hodgkin-lymphoma/.

44. Silas Inman. Juno accelerates development of JCAR017, Halts JCAR015. 2020. https://www.onclive.com/view/juno-accelera tes-development-of-jcar017-halts-jcar015.

45. Olson NE, Ragan SP, Ponko S, Trede NS, Stern HM, Sutherland $\mathrm{CL}$. Tumor gene signature associated with neurotoxicity in $\mathrm{R} / \mathrm{R}$ B-ALL patients treated with JCAR015, a CD19-directed CAR T cell product. J Clin Oncol. 2018;36 15_suppl:7007.

46. Gardner R, Finney O, Smithers H, Leger KJ, Annesley CE, Summers C, et al. CD19CAR T cell products of defined CD4: CD8 composition and transgene expression show prolonged persistence and durable MRD-Negative remission in pediatric and young adult B-Cell ALL. Blood. 2016;128:219.

47. Park JH, Riviere I, Wang X, Purdon T, Sadelain M, Brentjens RJ. Impact of disease burden on long-term outcome of $19-28 \mathrm{z}$ CAR modified $\mathrm{T}$ cells in adult patients with relapsed B-ALL. J Clin Oncol. 2016;34 15_suppl:7003.

48. Abramson JS, Palomba L, Gordon LI, Lunning M, Arnason J, Forero-Torres A, et al. Transcend NHL 001: Immunotherapy with the CD19-directed CAR T-cell product JCAR017 results in high complete response rates in relapsed or refractory B-cell Non-Hodgkin lymphoma. Blood. 2016;128:4192.

49. Bristol Myers Squibb. Bristol-Myers squibb announces submission of biologics license application for CAR T-cell therapy lisocabtagene maraleucel (liso-cel) to FDA. 2019. https://news.bms.com/ news/corporate-financial/2019/Bristol-Myers-Squibb-AnnouncesSubmission-of-Biologics-License-Application-for-CAR-T-CellTherapy-Lisocabtagene-Maraleucel-liso-cel-to-FDA/default.aspx. 
50. Bristol Myers Squibb. European Medicines Agency validates Bristol Myers Squibb's application for CAR T cell therapy lisocabtagene maraleucel (liso-cel). 2020. https://news.bms.com/ news/corporate-financial/2020/European-Medicines-Agency-Va lidates-Bristol-Myers-Squibbs-Application-for-CAR-T-CellTherapy-Lisocabtagene-Maraleucel-liso-cel/default.aspx.

51. Aleksandrova K, Leise J, Priesner C, Melk A, Kubaink F, Abken H, et al. Functionality and cell senescence of CD4/ CD8-Selected CD20 CAR T cells manufactured using the automated cliniMACS prodigy $^{\circledR}$ platform. Transfus Med Hemother. 2019;46:47-54.

52. Zhu F, Shah N, Xu H, Schneider D, Orentas R, Dropulic B, et al. Closed-system manufacturing of CD19 and dual-targeted CD20/ 19 chimeric antigen receptor $\mathrm{T}$ cells using the CliniMACS Prodigy device at an academic medical center. Cytotherapy. 2018;20:394-406.

53. CRISPR Therapeutics. CRISPR/Cas9 will drive the next generation of immuno-oncology cell therapy. 2020. http://www. crisprtx.com/programs/immuno-oncology.

54. Schubert M-L, Schmitt A, Neuber B, Huckelhoven-Krauss A, Kunz A, Wang L, et al. Third-generation CAR T cells targeting CD19 are associated with an excellent safety profile and might improve persistence of CAR T Cells in treated patients. Blood. 2019;134 Supplement_1:51.

55. Czuczman MS, Gregory SA. The future of CD20 monoclonal antibody therapy in B-cell malignancies. Leuk Lymphoma. 2010;51:983-94.

56. Kosmas C, Stamatopoulos K, Stavroyianni N, Tsavaris N, Papadaki T. Anti-CD20-based therapy of B cell lymphoma: state of the art. Leukemia. 2002;16:2004-15.

57. U.S. National Institutes of Health, Department of Health and Human Services. ClinicalTrials.gov: U.S. National Institutes of Health, Department of Health and Human Services. 2020. https:// clinicaltrials.gov/ct2/home.

58. Schlaak M, Schmidt P, Bangard C, Kurschat P, Mauch C, Abken H. Regression of metastatic melanoma in a patient by antibody targeting of cancer stem cells. Oncotarget. 2012;3:22-30. https:// pubmed.ncbi.nlm.nih.gov/22289880.

59. Schneider D, Xiong Y, Wu D, Nölle V, Schmitz S, Haso W, et al. A tandem CD19/CD20 CAR lentiviral vector drives ontarget and off-target antigen modulation in leukemia cell lines. J Immunother Cancer. 2017;5:42. https://pubmed.ncbi.nlm.nih. gov/28515942.

60. Shah NN, Maatman T, Hari P, Johnson B. Multi targeted CAR-T cell therapies for B-cell malignancies. Front Oncol. 2019;9:146. https://pubmed.ncbi.nlm.nih.gov/30915277.

61. Ehninger A, Kramer M, Röllig C, Thiede C, Bornhäuser M, Bonin Mvon, et al. Distribution and levels of cell surface expression of CD33 and CD123 in acute myeloid leukemia. Blood Cancer J. 2014;4:e218.

62. Hoyer JD, Grogg KL, Hanson CA, Gamez JD, Dogan A. CD33 detection by immunohistochemistry in paraffin-embedded tissues: a new antibody shows excellent specificity and sensitivity for cells of myelomonocytic lineage. Am J Clin Pathol. 2008; 129:316-23.

63. Arndt C, Bonin M, von, Cartellieri M, Feldmann A, Koristka S, Michalk I, et al. Redirection of T cells with a first fully humanized bispecific CD33-CD3 antibody efficiently eliminates AML blasts without harming hematopoietic stem cells. Leukemia. 2013;27:964-7.

64. Hauswirth AW, Florian S, Printz D, Sotlar K, Krauth M-T, Fritsch $\mathrm{G}$, et al. Expression of the target receptor CD33 in CD34+/CD38-/CD123+ AML stem cells. Eur J Clin Investig. 2007;37:73-82.

65. Cartellieri M, Feldmann A, Koristka S, Arndt C, Loff S, Ehninger A, et al. Switching CAR T cells on and off: a novel modular platform for retargeting of T cells to AML blasts. Blood Cancer J. 2016;6:e458.

66. Ehninger A, Cartellieri M, Feldmann A, Arndt C, Koristka S, Loff S, et al. Abstract 2313: Improved killing of tumor cells by a novel flexible antibody-based modular $\mathrm{T}$ cell retargeting system. Cancer Res. 2016;76:Abstract nr 2313.

67. Cartellieri M, Loff S, Bonin M, von, Bejestani EP, Ehninger A, Feldmann A, et al. Unicar: a novel modular retargeting platform technology for CAR T cells. Blood. 2015;126:5549.

68. Carpenter RO, Evbuomwan MO, Pittaluga S, Rose JJ, Raffeld $\mathrm{M}$, Yang S, et al. B-cell maturation antigen is a promising target for adoptive T-cell therapy of multiple myeloma. Clin Cancer Res. 2013;19:2048-60.

69. Cho S-F, Anderson KC, Tai Y-T, Targeting B. Cell maturation antigen (BCMA) in multiple myeloma: potential uses of BCMAbased immunotherapy. Front Immunol. 2018;9:1821.

70. Bristol Myers Squibb. Bristol Myers Squibb and bluebird bio announce submission of biologics license application (BLA) to FDA for Idecabtagene Vicleucel (Ide-cel, bb2121) for adults with relapsed and refractory multiple myeloma. 2020. https:// news.bms.com/news/corporate-financial/2020/Bristol-MyersSquibb-and-bluebird-bio-Announce-Submission-of-BiologicsLicense-Application-BLA-to-FDA-for-Idecabtagene-VicleucelIde-cel-bb2121-for-Adults-with-Relapsed-and-RefractoryMultiple-Myeloma/default.aspx.

71. Bristol Myers Squibb. European Medicines agency validates Bristol Myers Squibb's applications for Idecabtagene Vicleucel (Ide-cel, bb2121) and CC-486. 2020. https://news.bms.com/new s/corporate-financial/2020/European-Medicines-Agency-Valida tes-Bristol-Myers-Squibbs-Applications-for-IdecabtageneVicleucel-Ide-cel-bb2121-and-CC-486/default.aspx.

72. Garrett TE, Chekmasova AA, Evans JW, Seidel SL, Horton HM, Latimer HJ, et al. A BCMA-specific CAR T cell produced with clinically scalable lentiviral and $\mathrm{T}$ cell manufacturing processes has potent anti-multiple myeloma activity. J Immunother Cancer. 2015;3:124.

73. Raje N, Berdeja J, Lin Y, Siegel D, Jagannath S, Madduri D, et al. Anti-BCMA CAR T-cell therapy bb2121 in relapsed or refractory multiple myeloma. N Engl J Med. 2019;380:1726-37.

74. Munshi NC, Anderson LD, Shah N Jr, Jagannath S, Berdeja JG, Lonial S, et al. Idecabtagene vicleucel (ide-cel; bb2121), a BCMA-targeted CAR T-cell therapy, in patients with relapsed and refractory multiple myeloma (RRMM): Initial KarMMa results. J Clin Oncol. 2020;38 15_suppl:8503.

75. Madduri D, Usmani SZ, Jagannath S, Singh I, Zudaire E, Yeh T$\mathrm{M}$, et al. Results from CARTITUDE-1: a phase $1 \mathrm{~b} / 2$ study of JNJ-4528, a CAR-T cell therapy directed against B-cell maturation antigen (BCMA), in patients with relapsed and/or refractory multiple myeloma (R/R MM). Blood. 2019;134 Supplement_1:577.

76. Tai Y-T, Dillon M, Song W, Leiba M, Li X-F, Burger P, et al. Anti-CS1 humanized monoclonal antibody HuLuc63 inhibits myeloma cell adhesion and induces antibody-dependent cellular cytotoxicity in the bone marrow milieu. Blood. 2008;112:1329-37.

77. Miskey C, Amberger M, Reiser M, Prommersberger S, Beckmann J, Machwirth M, et al. Genomic analyses of SLAMF7 CAR-T cells manufactured by Sleeping Beauty transposon gene transfer for immunotherapy of multiple myeloma. bioRxiv. 2019. https://doi.org/10.1101/675009.

78. Hudecek M. THE CARAMBA PROJECT. 2020. https://www.ca ramba-cart.eu/the-project/.

79. Gogishvili T, Danhof S, Prommersberger S, Rydzek J, Schreder M, Brede C, et al. SLAMF7-CAR T cells eliminate myeloma and confer selective fratricide of SLAMF7+ normal lymphocytes. Blood. 2017;130:2838-47. 
80. Ma S, Li X, Wang X, Cheng L, Li Z, Zhang C, et al. Current progress in CAR-T cell therapy for solid tumors. Int J Biol Sci. 2019;15:2548-60.

81. BioNTech Cell \& Gene Therapies GmbH. BioNTech announces publication of preclinical data for first-in-kind CAR-T cell therapy approach targeting solid tumors in science. 2020. https:// investors.biontech.de/news-releases/news-release-details/ biontech-announces-publication-preclinical-data-first-kind-car-t/.

82. Reinhard K, Rengstl B, Oehm P, Michel K, Billmeier A, Hayduk $\mathrm{N}$, et al. An RNA vaccine drives expansion and efficacy of claudinCAR-T cells against solid tumors. Science. 2020;367:446-53.

83. Kranz LM, Diken M, Haas H, Kreiter S, Loquai C, Reuter KC, et al. Systemic RNA delivery to dendritic cells exploits antiviral defence for cancer immunotherapy. Nature. 2016;534:396-401.

84. Terme M, Ullrich E, Delahaye NF, Chaput N, Zitvogel L. Natural killer cell-directed therapies: moving from unexpected results to successful strategies. Nat Immunol. 2008;9:486-94.

85. Simonetta F, Alvarez M, Negrin RS. Natural killer cells in graftversus-host-disease after allogeneic hematopoietic cell transplantation. Front Immunol. 2017;8:465.

86. Liu E, Marin D, Banerjee P, Macapinlac HA, Thompson P, Basar $\mathrm{R}$, et al. Use of CAR-transduced natural killer cells in CD19positive lymphoid tumors. N Engl J Med. 2020;382:545-53.

87. Granzin M, Wagner J, Köhl U, Cerwenka A, Huppert V, Ullrich E. Shaping of natural killer cell antitumor activity by ex vivo cultivation. Front Immunol. 2017;8:458.

88. Burger MC, Zhang C, Harter PN, Romanski A, Strassheimer F, Senft C, et al. CAR-engineered NK cells for the treatment of glioblastoma: turning innate effectors into precision tools for cancer immunotherapy. Front Immunol. 2019;10:2683. https://www. frontiersin.org/article/10.3389/fimmu.2019.02683.

89. Tonn T, Becker S, Esser R, Schwabe D, Seifried E. Cellular immunotherapy of malignancies using the clonal natural killer cell line NK-92. J Hematother Stem Cell Res. 2001;10:535-44.
90. Zhang C, Oberoi P, Oelsner S, Waldmann A, Lindner A, Tonn T, et al. Chimeric antigen receptor-engineered NK-92 cells: an offthe-shelf cellular therapeutic for targeted elimination of cancer cells and induction of protective antitumor immunity. Front Immunol. 2017;8:533.

91. Cheng M, Zhang J, Jiang W, Chen Y, Tian Z. Natural killer cell lines in tumor immunotherapy. Front Med. 2012;6:56-66.

92. Tang X, Yang L, Li Z, Nalin AP, Dai H, Xu T, et al. First-in-man clinical trial of CAR NK-92 cells: safety test of CD33-CAR NK92 cells in patients with relapsed and refractory acute myeloid leukemia. Am J Cancer Res. 2018;8:1083-9.

93. Gong JH, Maki G, Klingemann HG. Characterization of a human cell line (NK-92) with phenotypical and functional characteristics of activated natural killer cells. Leukemia. 1994;8:652-8.

94. Fang F, Xiao W, Tian ZNK. cell-based immunotherapy for cancer. Semin Immunol. 2017;31:37-54.

95. Klingemann H, Boissel L, Toneguzzo F. Natural killer cells for immunotherapy - advantages of the NK-92 cell line over blood NK cells. Front Immunol. 2016;7:91.

96. Antony GK, Dudek AZ. Interleukin 2 in cancer therapy. Curr Med Chem. 2010;17:3297-302.

97. Zhang C, Burger MC, Jennewein L, Genßler S, Schönfeld K, Zeiner P, et al. ErbB2/HER2-Specific NK cells for targeted therapy of glioblastoma. J Natl Cancer Inst. 2016;108.

98. Ahmed N, Brawley V, Hegde M, Bielamowicz K, Kalra M, Landi D, et al. HER2-specific chimeric antigen receptor-modified virus-specific $\mathrm{T}$ cells for progressive glioblastoma: a phase 1 dose-escalation trial. JAMA Oncol. 2017;3:1094-101.

99. Maldini CR, Ellis GI, Riley JLCAR. T cells for infection, autoimmunity and allotransplantation. Nat Rev Immunol. 2018; 18:605-16.

100. Namdari H, Rezaei F, Teymoori-Rad M, Mortezagholi S, Sadeghi A, Akbari A. CAR T cells: Living HIV drugs. Rev Med Virol. 2020;30:1-14. 